\title{
Balloon dilatation of native coarctation of aorta in infants - short term clinical result
}

\author{
Oswal N ${ }^{1}$, Doshi $D^{2}$, Jadhav $N^{3}$, Humane $D^{4}$, Sharma K ${ }^{5}$, Shah $K^{6}$ \\ ${ }^{1}$ Dr. Nilesh Oswal, Senior Consultant and Assistant Professor, Pediatric Cardiology, Department of Cardiology, ${ }^{2}$ Dr. \\ Dhaval Doshi, Assistant Professor, Department of Cardiology, ${ }^{3}$ Dr. Nikhil Jadhav, Assistant Professor, Department of \\ Cardiology, ${ }^{4}$ Dr. Dhammdeep Humane, Resident, Department of Cardiology, ${ }^{5}$ Dr. Kamal Sharma, Associate Professor, \\ Department of Cardiology, ${ }^{6}$ Dr. Komal Shah, Research Officer, Department of Research, All authors are affiliated with U. \\ N. Mehta Institute of Cardiology and Research Centre, Civil Hospital Campus, Ahmedabad, Gujarat, India.
}

Address for Correspondence: Dr. Nilesh Oswal, Department of Cardiology, U. N. Mehta Institute of Cardiology and Research Centre, Civil Hospital Campus, Ahmedabad, Gujarat, India. Email: nilesh.oswal@yahoo.com

\begin{abstract}
Background: Balloon dilatation with or without placement of stent in native coarctation offers a good alternative to surgery. Aim: To determine feasibility and safety of primary balloon angioplasty in infants with coarctation of aorta. Materials and Methods: This was a retrospective, observational study of 44 consecutive infants undergoing balloon dilatation of native coarctation of aorta during a 4 year period from July 2009 to July 2013. Demographic details, previous history and data of chest X-ray, electrocardiogram and sequential echocardiography were collected for all the patients. The patients were followed up at 1 months, 6 months and 1 year thereafter. Results: The reintervention rate was $20.45 \%$ after successful procedure. Two patients having hypoplastic arch had successful procedure with 1 requiring reintervention. Left ventricular dysfunction was observed in 15 patients, out of them 11 patients improved immediately after the procedure. Thirty five (79.55\%) patients did not undergo reintervention in whom mean gradient was reduced from $48.05 \pm 15.26 \mathrm{~mm}$ $\mathrm{Hg}$ to $10.97 \pm 5.8 \mathrm{~mm} \mathrm{Hg}$ after percutaneous reintervention $(\mathrm{p}<0.0001)$. Also, mean diameter in this group was improved $(1.94 \pm 0.52 \mathrm{vs} 6.07 \pm 1.84 \mathrm{~mm} ; \mathrm{p}<0.0001)$. Early age of presentation was identified as a contributor of reintervention in the study population $(\mathrm{p}=0.009)$. Conclusions: This study results show that BDC in infants is a safe and feasible technique that could be effectively used as an option of surgery in order to reduce mortality and morbidity.
\end{abstract}

Keywords: Coarctation of aorta, Balloon angioplasty, Infants.

\section{Introduction}

A natural history study shows that the median survival in untreated Coarctation of Aorta (COA) is 31 years [1]. In infants with ductal closure, there is development of increased pressure load resulting in myocardial dilation, myocardial dysfunction and reduced stroke volume leading to symptoms of congestive heart failure and cardiogenic shock. Though surgical management has been advocated as treatment of choice in these infants with native coarctation of aorta, feasibility of surgery and associated morbidity has to be thought of. Balloon dilatation with or without placement of stent in native coarctation is an accepted mode of treatment in older children. Wong et al. in a systematic decision analysis

Manuscript received: $7^{\text {th }}$ January 2017

Reviewed: $15^{\text {th }}$ January 2017

Author Corrected: $22^{\text {nd }}$ January 2017

Accepted for Publication: $28^{\text {th }}$ January 2017 to compare balloon angioplasty and surgery in children of different age groups found balloon angioplasty to be preferable over surgery in the non-neonatal coarctation patients, whereas balloon angioplasty in infants remains controversial [2].

Due to the balloon dilation, high incidence of tears, dissections, subsequent aneurysm formation and restenosis has been noted and hence, primary balloon angioplasty for native coarctation of aorta is considered as high risk procedure. However, there are only limited number of studies on primary balloon angioplasty for native coarctation of aorta in neonates, infants and young children. This study determines feasibility and safety of primary balloon angioplasty in infants with coarctation of aorta. 


\section{Materials and Methods}

Patients and study design- We performed retrospective analysis of 44 consecutive infants who underwent balloon dilatation of native coarctation of aorta during a 4 year period from July 2009 to July 2013 at our institute.

All symptomatic and asymptomatic patients with severe coarctation of aorta with mean gradient of $>20 \mathrm{~mm}$ of $\mathrm{Hg}$ across narrow segment were included in the study. Patients of interrupted arch and with any prior intervention for coarctation of aorta were excluded from the study.

Informed written consent was obtained from parents of each patient and approval of ethics committee was taken. All the enrolled patients underwent detailed history and physical examination. Data was collected for the symptoms which brought the patients to clinician's attention. A chest x-ray, electrocardiogram, detailed sequential echocardiogram study were performed for each patient.

Procedure-Conscious sedation was given with ketamine infusion $(50 \mu \mathrm{gm} / \mathrm{kg} / \mathrm{min})$ in most of the patients while mechanical ventilation with general anesthesia was instituted in patients with cardiogenic shock, respiratory distress or in patients developing distress during procedure.

A pediatric introducer sheath of $4 \mathrm{~F}$ was inserted in the femoral artery and complete anticoagulation was achieved with $100 \mathrm{U} / \mathrm{Kg}$ of unfractationed heparin. 0.035 " J-tipped Terumo wire with Judkins right coronary catheter was used to cross narrowest segment in most of the patients. However in

some of the severely narrowed segments coronary wire was used to cross the narrowest segment. Angiogram was performed in $20^{\circ}$ left anterior oblique and lateral views and peak to peak gradient was measured across the narrowest segment with end hole catheter.

Diameter of ascending aorta, transverse arch, isthmus, narrowest segment, proximal descending aorta and descending thoracic aorta at diaphragm level were measured from cineangiogram. Balloon dilation of coarctation of aorta was performed with coronary balloons over the coronary wire and was inflated with pressure gauge inflators.

The size of the balloon was determined on angiography with reference to diameter of isthmus. Repeat angiogram and pressure gradients were taken after balloon dilatation to determine success of procedure.

Follow-up- Follow-up evaluation was done at 1 month, 6 months and yearly thereafter. Evaluation included clinical examination focusing on symptoms and physical examination with upper limb/lower limb blood pressure determinations by sphygmomanometer, electrocardiography, and echocardiography.

Statistics-Patient and procedural characteristics are expressed as frequencies, mean $\pm \mathrm{SD}$ or median and range. The entire tests were two sided. Data obtained prior to and immediately after the balloon dilatation were compared using a paired t-test. The differences between subgroups were tested by t-test.

\section{Results}

We assessed 44 infants in this study of which 5 were female. Mean age at presentation was $99.19 \pm 227.4$ days and average weight was $4.18 \pm 2.13 \mathrm{Kg}$. Twenty five $(56.82 \%)$ of the patients had isolated coarctation, whereas 16 patients had associated acyanotic congenital heart disease while 1 patients were diagnosed with cyanotic congenital heart disease. Bicuspid aortic valve was present in 21 patients (47.7\%) while transverse hypoplastic arch was found in 2 patients (4.5\%) (Table 1).

Fifteen (34.09\%) patients had left ventricular dysfunction on presentation. Mean diameter of coarctation segment increased from $2.068 \pm 1.24$ to $7.04 \pm 2.03$ ( -value $<0.0001$ ) and peak gradient reduced from $46.3 \pm 18.35 \mathrm{~mm} \mathrm{Hg}$ to $10.47 \pm 11.97 \mathrm{~mm}$ $\mathrm{Hg}$ after the procedure ( $\mathrm{p}$-value $<0.001)$.

The reintervention rate was $20.45 \%$ after successful procedure. Average hospital stay was $6.11 \pm 3.68$ days. Left ventricular function improved immediately in 11 patients after the procedure. Total follow up period was 12 months. Total 9 patients $(20.45 \%)$ developed re-coarctation of aorta on median follow up of the 19 weeks. Mean gradient in re-coarctation cohort was $49.11 \pm 13.12 \mathrm{~mm} \mathrm{Hg}$ which reduced to $10.33 \pm 5.6 \mathrm{~mm} \mathrm{Hg}$ after percutaneous reintervention $(\mathrm{p}<0.0001)$.

Mean diameter in recoarctation group increased from $1.68 \pm 0.59$ to $5.86 \pm 1.34 \mathrm{~mm}$ after re-intervention $(\mathrm{p}<0.0001)$. The improvement in gradient in both the groups (non-intervention and reintervention are presented in (figure 1). 
Table 1: Characteristic of the study group.

\begin{tabular}{|c|c|}
\hline Male/Female & $39 / 5$ \\
\hline Age (Days) & $99.19 \pm 227.4$ \\
\hline Mean & $3-246$ \\
\hline Range & $4.18 \pm 2.13$ \\
\hline Weight (kg) & $1.5-6.2$ \\
\hline Median & 25 \\
\hline Range & 2 \\
\hline Diagnoses & 16 \\
\hline Isolated Coarctation including bicuspid aortic valve & 1 \\
\hline Coarctation with Hypoplastic arch & 15 \\
\hline Coarctation with acynotic congenital heart disease & \\
\hline
\end{tabular}
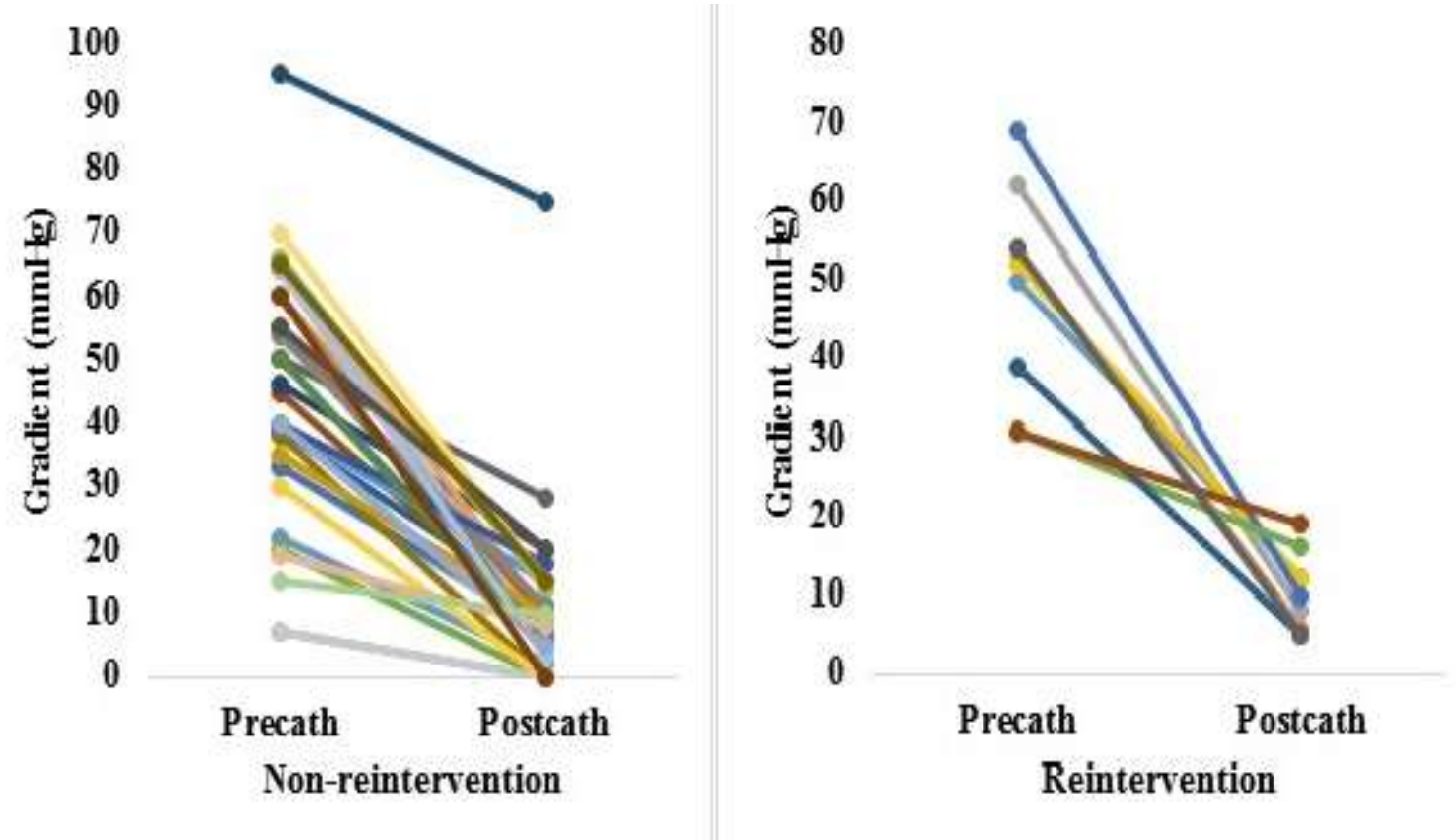

Figure-1: Comparison of gradient (pre vs post procedure) in non-reintervention and reintervention group.

Both the patients with hypoplastic arch had successful procedure, out of them 1 had incidence of reintervention and another is on follow up. Factors affecting early reintervention of BDC are presented in (table 2). Younger age of presentation was identified as a contributor of reintervention in the study population.

Average balloon size used was $162 \%$ of isthmus size and $110 \%$ of diameter of descending thoracic aorta at diaphragm level and it showed no significant correlation with restenosis rate. Eight patients had reintervention in form of balloon dilatation while 1 patient underwent surgical arch repair. On median follow-up of 8 months all patients with re-intervention were asymptomatic with no patient having significant residual gradient. The freedom from reintervention after first attempt was $78.5 \%$ at 4 months and subsequent freedom from reintervention after second balloon dilation was $100 \%$ at 8 months. 
Table-2: Factors affecting early reintervention

\begin{tabular}{|c|c|c|c|}
\hline & Non reintervention & reintervention & p Value \\
\hline Patients & 35 & 9 & \\
\hline Age (Days) Mean & 102 & 76 & 0.03 \\
\hline Weight (kg) Mean & 4.7 & 4.2 & 0.07 \\
\hline Ballon/to Coarctation ratio & $2.43 \pm 0.69$ & $2.32 \pm 0.81$ & 0.157 \\
\hline Descending thoracic aorta dimension (mm) & $5.93 \pm 1.45$ & $5.1 \pm 1.48$ & 0.278 \\
\hline Transverse arch to descending aortic dimensions (mm) & $0.97 \pm 0.19$ & $0.96 \pm 0.13$ & 0.157 \\
\hline Pre procedural coarctation diameter (mm) & $1.94 \pm 0.52$ & $1.68 \pm 0.59$ & 0.278 \\
\hline Pre procedural gradient (mm hg) & $48.05 \pm 15.26$ & $49.11 \pm 13.12$ & 0.902 \\
\hline Post procedural coarctation diameter (mm) & $6.07 \pm 1.84$ & $5.86 \pm 1.34$ & 0.87 \\
\hline Post procedural gradient (mm hg) & $10.97 \pm 5.8$ & $10.33 \pm 5.6$ & 0.96 \\
\hline z-value of transverse arch & $-2.83 \pm 1.55$ & $-3.63 \pm 2.80$ & 0.355 \\
\hline Balloon/ DTA dimension ratio & 1.06 & 1.00 & 0.98 \\
\hline
\end{tabular}

Four patients had transient loss of pulse after procedure which was appropriately treated with anticoagulation for 24 hours. However, patients with severe left ventricular dysfunction needed inotropic support for at least 1-2 days.

\section{Discussion}

Significant advances in recent years have enabled the increasing application of interventional catheterization techniques to pediatric groups. Developments in catheters, balloons and guide wires have led to improved performance and to relatively simple, low-risk procedures that can be used in infants. Lock et al performed the first balloon angioplasty in excised segments of human COA [3]. Since then, balloon dilatation has become a standard method of treatment in both native and recurrent $\mathrm{COA}[4,5]$.

Treatment of coarctation is indicated when the obstruction gradient during cardiac catheterization is $\geq$ $20 \mathrm{mmHg}$ [6]. In the present study significant coarctation of aorta was defined as peak gradient of $\geq 20 \mathrm{~mm} \mathrm{Hg}$ and all the patients had peak gradient $\geq 20 \mathrm{~mm} \mathrm{Hg}$. In the present study 7 infants had severe left ventricular dysfunction with metabolic acidosis on presentation. Prompt correction of acidosis was done and PGE1 infusion was started.

All patients responded well and balloon dilatation was done in the next 24 to $48 \mathrm{hrs}$. The role of PGE1 in such cases has been supported by study done by Freed et al who found dilatation of ductus with minimization of obstruction within $3 \mathrm{hrs}$ in $80 \%$ of such cases [7]. Twenty five out of 26 neonates $(96 \%)$ had successful immediate outcome of balloon dilatation in the present study. This rate is in accordance with that of Yetman and coworkers [8]. There was significant decrease in mean gradient and increase in mean diameter of narrowest segment immediately after the procedure. Similar success rate has been reported by Farouk et al in their study in immediate post procedure period [9].

However, at 4 months post balloon dilatation the procedure was considered effective in 20 out of the 26 (76.9\%) patients. Six neonates $(23.0 \%)$ developed recoarctation of aorta on median follow up of 19 weeks. This is in accordance with Redington et al.

Who in their study has reported high rate of restenosis after balloon angioplasty in neonates [10]. Similarly, Patel et al also reported high incidence of restenosis in neonates after balloon dilatation for coarctation of aorta in similar subset of patients [11].

This is explained by risk for restenosis in neonates and infants in the follow up period due to presence of large amount of myoblasts around the coarctation site [12]. Other reason for re-coarctation could be due to neointimal hyperplasia caused by fracture of the internal elastic lamina and the migration of smooth muscle cells and fibroblasts from tunica media to intima and their 
proliferation may cause restenosis after balloon angioplasty for aortic coarctation [13].

Beekman et al reported femoral artery injuries and thrombosis in $21 \%$ of newborns and infants, and in $9 \%$ of children in their study [14]. Similarly, in our study $9.0 \%$ infants had transient loss of femoral pulse which was reestablished within $24 \mathrm{hrs}$ with adequate anticoagulation. In the present study no significant correlation was found between pre-procedure mean gradient, post procedure mean diameter achieved and recoarctation rate.

Also, no correlation was found with hypoplastic transverse arch and restenosis rate due to inadequate number $(n=2)$ of patients with hypoplastic transverse arch. Similar to present study Reigh et al also could not found any predictors for re-coarctation except for age at percutaneous intervention [15].

However, Yetman et al have reported transverse arch hypoplasia, higher pre-angioplasty pressure gradient and a higher pressure gradient immediately after angioplasty as predictors for reintervention [8]. In an another study by Kaine et al young patient age (neonate), associated arch hypoplasia and a small COA diameter were the factors associated significantly with re-coarctation of aorta [16].

Nine patients underwent re-intervention of which 8 patients underwent balloon dilatation after a median follow up period of 19 weeks. Various studies has reported re-intervention rate between 6 to $53 \%$ for recoarctation of aorta. Procedural success rate was $100 \%$ in our study. This success rate was higher than is reported in other studies $[8,15]$.

In re-intervention cohort no patient developed any major procedure related complications. While other studies have reported complication rate up to $17 \%$ [17]. Other associated cardiac anomalies also affect outcome in coarctation of aorta [18].

In our study $36.36 \%$ patients had associated acyanotic congenital heart disease while $2.2 \%$ patients had complex cyanotic congenital heart disease. One patient died 4 days after procedure with septicemia, had associated large ventricular septal defect with severe pulmonary artery hypertension.

Similar to our study Beekman et al also reported higher incidence of morbidity and mortality with associated cardiac anomalies and left ventricular dysfunction in their study [14].

One patient in our study underwent surgical repair after re-coarctation of aorta. Patient was asymptomatic with no significant residual gradient at 8 months of follow up after surgical repair. Following balloon dilatation restenosis treated with surgical repair has restenosis rate of $7 \%$ to $30 \%$ [19]. No patient in our study in reintervention group developed any complications during procedure or in follow up period.

Limitation of the study- The study includes small number of patient, is a retrospective study, without surgical controls and follow up is up to term.

\section{Conclusion}

This study shows balloon dilation of coarctation of aorta in infants is feasible, safe and have low incidence of reintervention. Patient presenting with left ventricular dysfunction had remarkable improvement in ventricular function after balloon dilation, hence it can be used as a rescue procedure for infants presenting in morbid condition. We could identify younger age of presentation as a statistical significant predicator for reintervention.

Funding: Nil, Conflict of interest: None initiated, Perission from IRB: Yes

\section{References}

1. Jenkins NP, Ward C. Coarctation of the aorta: natural history and outcome after surgical treatment. QJM 1999; 92(7):365-71.

2. Wong D, Benson LN, Van Arsdell GS, Karamlou T, McCrindle BW. Balloon angioplasty is preferred to surgery for aortic coarctation. Cardiol. Young 2008; 18 (1):79-88.DOI:10.1017/S1047951107001795.

3. Lock JE, Castaneda-Zuniga WR, Bass JL, Foker JE, Amplatz K, Anderson RW. Balloon dilatation of excised aortic coarctations. Radiology. 1982; 143(3): 689-91. DOI: 10.1148/radiology.143.3.6210934.

4. Hijazi ZM, Fahey JT, Kleinman CS, Hellenbrand WE. Balloon angioplasty for recurrent coarctation of aorta. Immediate and long-term results. Circulation 1991; 84(3): 1150-56. DOI: https://doi.org/10.1161/01. CIR.84.3.1150.

5. Ovaert C, McCrindle BW, Nykanen D, MacDonald C, Freedom RM, Benson LN.. Balloon angioplasty of 
native coarctation: clinical outcomes and predictors of success. J Am Coll Cardiol. 2000; 35(4): 988-96. DOI: http://dx.doi.org/10.1016/S0735-1097(99)00646-4.

6. Hamdan MA, Maheshwari S, Fahey JT, Hellenbrand WE. Endovascular stents for coarctation of the aorta: initial results and intermediate-term follow-up. J Am Coll Cardiol. 2001; 38(5):1518-23. DOI: http://dx.doi. org/10.1016/S0735-1097(01)01572-8

7. Freed MD, Heymann MA, Lewis AB, Roehl SL, Kensey RC. Prostaglandin E1 infants with ductus arteriosus-dependent congenital heart disease. Circulation 1981;64(5):899-905.DOI: https://doi. org/ 10. 1161/01.CIR.64.5.899

8. Yetman AT, Nykanen D, Mc Crindle BW, Sunnegardh J, Adatia I, Freedom RM, Benson L. Balloon angioplasty of recurrent coarctation. J Am Card. 1997; 30(3):811-16. DOI: http://dx.doi.org/10. 1016 / S0735-1097(97)00228-3.

9. Mohammed Farouk, Ahmed El Ayadi, Sonia El Saeidy. Improvement of Left Ventricular Mass Following Balloon Angioplasty of Native Coarctation of the Aorta: Midterm follow-up in Cairo University, Children's Hospital. Br J Med Med Res. 2013; 3(4): 1271-84. DOI: 10.9734/BJMMR/2013/3262.

10. Rao PS. Balloon angioplasty for coarctation of the aorta in infancy. J Pediatr. 1987; 110(5):713-18

11. Redington AN, Booth Phillip, Shore DF, Rigby ML. Primary balloon dilatation of coarctation of the aorta in neonates. Br Heart J. 1990; 64(4):277-81.

12. Rao PS. Balloon angioplasty of native coarctation of the aorta. J. Invasive Cardiol. 2000; 12(8):407-9.

13. Ohkubo M, Takahashi K, Kishiro M, Akimoto K, Yamashiro Y. Histological findings after angioplasty using conventional balloon, radiofrequency thermal balloon, and stent for experimental aortic coarctation. Pediatr Int. 2004; 46(1):39-47. DOI: 10.1111/j.13280867. 2004.t01-1-.x

14. Beekman RH, Rocchini AP, Dick M 2nd, Snider AR, Crowley DC, Serwer GA, Spicer RL, Rosenthal A. Percutaneous balloon angioplasty for native coarctation of the aorta. J Am Coll Cardiol. 1987; 10(5):1078-84.

15. Oleg Reich, Petr Tax, Helena Bartáková, Viktor Tomek, Jiří Gilík, Jiř́ Lisý, Jiří Radvanský, Tomáš Matějka, Tomáš Tláskal, IrenaSvobodová, Václav Chal oupecký, Jan Škovránek. Long-term (up to 20 years) results of percutaneous balloon angioplasty of recurrent aortic coarctation without use of stents: Eur Heart J. 2008; 29(16): 2042-48 DOI: http://dx.doi. org/ 10. 1093/eurheartj/ehn251.

16. Kaine SF, O'Brian Smith E, Mott AR, Mullins CE, Geva T. Quantitative echocardiographic analysis of the aortic arch predicts outcome of balloon angioplasty of native coarctation of the aorta. Circulation. 1996; 94 (5):1056-62.https://doi.org/10.1161/01.CIR.94.5. 1056.

17. Erbel R, Gorge G, Gerber T, Ge J, Thelen M, Rumpelt $\mathrm{HJ}$, et al. Dissection following balloon angioplasty of aortic coarctation: review of the literature. J Interv Cardiol. 1992; 5(2):99-109. DOI: 10. 1111/j.1540-8183.1992.tb00414.x

18. Webb GD, Smallhorn JF, Therrien J, Redington AN. Congenital heart disease. In: Bonow RO, Mann DL, Zipes DP, and Libby P (eds). Braunwald's Heart Disease: A textbook of cardiovascular medicine, 9th edition. Philadelphia, WB Saunders. 2011; 65:1412-67.

19. Maheshwari S, Bruckheimer E, Fahey JT, Hellenbrand WE. Balloon angioplasty of postsurgical recoarctation in infants: the risk of restenosis and longterm follow-up. J Am Coll Cardiol. 2000; 35(1):209-13. DOI: http://dx.doi.org/10.1016/S0735-1097(99)00527-6

\section{How to cite this article?}

Oswal N, Doshi D, Jadhav N, Humane D, Sharma K, Shah K. Balloon dilatation of native coarctation of aorta in infants short term clinical result. J PediatrRes.2017;4(01):52-57.doi:10.17511/ijpr.2017.i01.11 